\title{
Functional Alterations in Cerebellar Functional Connectivity in Anxiety Disorders
}

\author{
Yoon Ji Lee ${ }^{1}$ (D) Xavier Guell ${ }^{2}$. Nicholas A. Hubbard ${ }^{3,4}$ - Viviana Siless ${ }^{5} \cdot$ Isabelle R. Frosch ${ }^{4}$ - Mathias Goncalves ${ }^{4}$. \\ Nicole Lo ${ }^{4}$ - Atira Nair ${ }^{1}$ - Satrajit S. Ghosh ${ }^{5,6}$. Stefan G. Hofmann ${ }^{7}$. Randy P. Auerbach ${ }^{8}$ - Diego A. Pizzagalli ${ }^{9}$. \\ Anastasia Yendiki $^{5,6} \cdot$ John D.E. Gabrieli ${ }^{4}$. Susan Whitfield-Gabrieli ${ }^{1,4} \cdot$ Sheeba Arnold Anteraper $^{1}$
}

Accepted: 8 November 2020 / Published online: 18 November 2020

(C) The Author(s) 2020

\begin{abstract}
Adolescents with anxiety disorders exhibit excessive emotional and somatic arousal. Neuroimaging studies have shown abnormal cerebral cortical activation and connectivity in this patient population. The specific role of cerebellar output circuitry, specifically the dentate nuclei (DN), in adolescent anxiety disorders remains largely unexplored. Resting-state functional connectivity analyses have parcellated the DN, the major output nuclei of the cerebellum, into three functional territories (FTs) that include default-mode, salience-motor, and visual networks. The objective of this study was to understand whether FTs of the DN are implicated in adolescent anxiety disorders. Forty-one adolescents (mean age $15.19 \pm 0.82,26$ females) with one or more anxiety disorders and 55 age- and gender-matched healthy controls completed resting-state fMRI scans and a self-report survey on anxiety symptoms. Seed-to-voxel functional connectivity analyses were performed using the FTs from DN parcellation. Brain connectivity metrics were then correlated with State-Trait Anxiety Inventory (STAI) measures within each group. Adolescents with an anxiety disorder showed significant hyperconnectivity between salience-motor DN FT and cerebral cortical salience-motor regions compared to controls. Salience-motor FT connectivity with cerebral cortical sensorimotor regions was significantly correlated with STAI-trait scores in HC $\left(R^{2}=0.41\right)$. Here, we report DN functional connectivity differences in adolescents diagnosed with anxiety, as well as in $\mathrm{HC}$ with variable degrees of anxiety traits. These observations highlight the relevance of DN as a potential clinical and sub-clinical marker of anxiety.
\end{abstract}

Keywords Anxiety $\cdot$ Cerebellum $\cdot$ Dentate nucleus $\cdot$ Salience network $\cdot$ Motor network

Sheeba Arnold Anteraper

s.anteraper@northeastern.edu

1 Department of Psychology, ISEC 672D, Northeastern University, Boston, MA 02115, USA

2 Massachusetts General Hospital, Boston, MA, USA

3 University of Nebraska-Lincoln, Lincoln, NE, USA

4 Massachusetts Institute of Technology, Cambridge, MA, USA

5 Athinoula A. Martinos Center for Biomedical Imaging, Massachusetts General Hospital, Boston, MA, USA

6 Harvard Medical School, Boston, MA, USA

7 Boston University, Boston, MA, USA

8 Columbia University, New York, NY, USA

9 McLean Hospital, Belmont, MA, USA

\section{Introduction}

Anxiety disorders are the most common mental illnesses among adolescents, with the median age of onset at 11 years and a lifetime prevalence rate of $31.9 \%$ during adolescence $[1$, 2]. Adolescence is a unique developmental period during which sensitivity to affective information peaks and emotional responses to stimuli are particularly intense [3]. Adolescent anxiety disorders may thus lead to prolonged psychosocial problems and be a precursor to other psychiatric disorders such as major depressive disorders [4]. Neurocognitive studies on adolescent anxiety have mostly focused on amygdala and prefrontal cortex due to their roles in emotion- and cognitive control-related behaviors [5-7]. However, anxiety disorders are associated with widespread network disruption [8].

Anxiety disorders are characterized by the exaggerated aversive response to actual or perceived threatening 
stimuli, often accompanied by emotional, cognitive, and somatic arousal [9]. One region implicated in motor, cognitive, and emotional processes involved in anxiety disorders is the cerebellum. Neuroimaging studies have highlighted cerebellar changes associated with anxiety disorders. Specifically, increased cerebellar gray matter volume has been reported in social anxiety disorder [10] and specific phobia [11]. Relative to healthy participants, patients with anxiety disorders have shown enhanced cerebellar activity when presented with angry faces [12], social tasks [13], and at rest [14]. Patients with anxiety disorders also display changes in cerebellar functional connectivity with anxiety-related regions in the cerebral cortex, such as the limbic system and prefrontal cortical areas. For example, enhanced connectivity between cerebellum and amygdala, a core structure implicated in emotion processing, has been reported in multiple studies of generalized anxiety disorder $[5,7,15]$. Furthermore, in patients with anxiety disorders, the cerebellum has shown aberrant intrinsic connectivity with the salience network $[16,17]$, default-mode network (DMN) [18], and centralexecutive networks (Hilber et al.) [19] during resting-state functional magnetic resonance imaging (fMRI). Such alterations in cerebellar connectivity are also evident in non-clinical populations with high state or trait anxiety $[20,21]$, suggesting that the cerebellum has a role in anxiety susceptibility.

Although a cerebellar role in anxiety disorders has been evidenced in the literature, prior investigation has rarely examined abnormalities in the cortico-cerebellar functional networks of adolescents with anxiety disorders. The cerebellum communicates with cortical regions by projecting to the deep cerebellar nuclei, the largest of which is the dentate nuclei (DN). DN projects first synapse in the thalamus, and then projects to frontal, motor, and parietal cortices, allowing the cerebellum to contribute to virtually all streams of information processing in the cerebral cortex $[22,23]$. As the cerebellum serves a wide range of functions and is suggested to be composed of discrete regions dedicated to unique functions [24, 25], we aimed to identify whether alterations in cerebellar functional connectivity in adolescent anxiety are predominantly located within a specific functional territory within the DN or whether these alterations are present in all aspects of the DN. Here, we employed the functional parcellations of DN, the major cerebellar output nuclei, from Guell et al.'s [26] research, which parcellated the DN into three territories with specific functional connections to default-mode, salience-motor, and visual networks in the cerebral cortex using resting-state fMRI scans in a healthy population. We used these three DN functional territories (FTs) as seed regions of interest (Fig. 1) to newly examine the intrinsic functional connectivity of cortico-cerebellar network in adolescent anxiety disorders and investigate its relationship with individual differences in anxious symptoms.

\section{Methods}

\section{Study Participants and Procedure}

Adolescents aged 14-17 diagnosed with anxiety disorders $($ Anx $=41$; mean age $=15.19)$ and matched healthy controls $(\mathrm{HC}=55$, mean age $=15.31)$ were enrolled in the Boston Adolescent Neuroimaging of Depression and Anxiety (BANDA) project. Clinical characteristics, diagnostic criteria, and demographics information have been previously reported (see $[27,28]$ ). Sample clinical characteristics are summarized in Table 1.
Fig. 1 Structural location and FTs of the dentate nuclei as reported in [26]). Red, FT1 = default-mode network FT. Blue, FT2 = salience-motor FT. Green, FT3 = visual FT
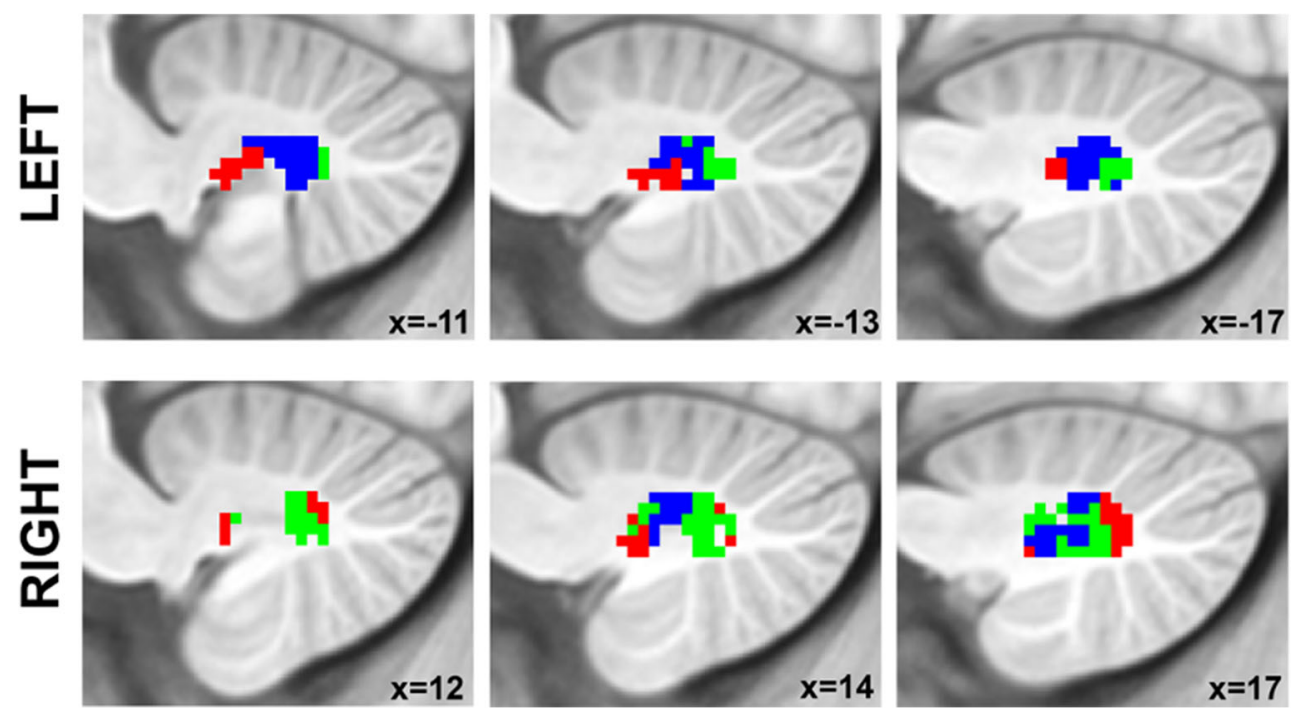
Table 1 Demographics

\begin{tabular}{|c|c|c|c|}
\hline & Anx & $\mathrm{HC}$ & $p$ value \\
\hline \multicolumn{4}{|l|}{ Demographics } \\
\hline Total participants & 41 & 55 & \\
\hline Mean age (years) & $15.19 \pm 0.82$ & $15.31 \pm 0.86$ & $p=0.51$ \\
\hline Sex: female & $26(63)$ & $31(56)$ & \\
\hline Handedness: right-handed & $39(95)$ & $46(83)$ & \\
\hline Full-scale WASI score & $115.80 \pm 16.40$ & $118.13 \pm 14.11$ & $p=0.47$ \\
\hline STAI: trait score & $43.98 \pm 9.67$ & $30.45 \pm 7.44$ & $p<0.001$ \\
\hline STAI: state score & $39.4 \pm 10.49$ & $29.18 \pm 8.04$ & $p<0.001$ \\
\hline Psychotropic medication treatment & $18(44)$ & 0 & \\
\hline \multicolumn{4}{|l|}{ Quality assurance } \\
\hline No. of invalid scans & 123.88 & 109.11 & $p=0.45$ \\
\hline Max motion & 0.69 & 0.53 & $p=0.37$ \\
\hline Mean motion & 0.06 & 0.06 & $p=0.98$ \\
\hline \multicolumn{4}{|l|}{ Anxiety disorders } \\
\hline Generalized anxiety disorder & $23(56)$ & 0 & \\
\hline Social anxiety disorder & $18(44)$ & 0 & \\
\hline Overanxious disorder & $17(41)$ & 0 & \\
\hline ADHD & $11(27)$ & 0 & \\
\hline Specific phobia & $9(22)$ & 0 & \\
\hline Oppositional defiant disorder & $5(12)$ & 0 & \\
\hline OCD/excoriation disorder & $5(12)$ & 0 & \\
\hline Separation anxiety & $4(10)$ & 0 & \\
\hline Avoidant personality disorder & $4(10)$ & 0 & \\
\hline Panic disorder & $4(10)$ & 0 & \\
\hline Substance use disorder & $1(2.4)$ & 0 & \\
\hline PTSD & $1(2.4)$ & 0 & \\
\hline Others & $4(10)$ & 0 & \\
\hline \multicolumn{4}{|l|}{ Types of medication treatment } \\
\hline Serotonin reuptake inhibitor (SSRI) & $14(78)$ & 0 & \\
\hline Stimulant & $4(22)$ & 0 & \\
\hline Antipsychotic drug & $1(6)$ & 0 & \\
\hline Benzodiazepine & $1(6)$ & 0 & \\
\hline Tricyclic antidepressant & $1(6)$ & 0 & \\
\hline Anxiolytic agent & $1(6)$ & 0 & \\
\hline Alpha-agonist agent & $1(6)$ & 0 & \\
\hline Anticonvulsant & $1(6)$ & 0 & \\
\hline
\end{tabular}

Values expressed as $n(\%)$ or mean \pm standard deviation; WASI, Wechsler Abbreviated Scale of Intelligence; $A D H D$, attention-deficit/hyperactivity disorder; $O C D$, obsessive-compulsive disorder; $P T S D$, post-traumatic stress disorder; Others include Tourette syndrome, enuresis, misophonia, and unspecified anxiety disorder

Informed consent was obtained from legal guardians and assent was obtained from the adolescent. Adolescent-parent dyads were administered the KSADS to assess adolescent lifetime mental disorders, and the State-Trait Anxiety Inventory (STAI; [29]) was used to assess continuous anxiety. The STAI is a commonly used self-report questionnaire that measures both anxiety levels rooted in the personality (STAItrait) and anxiety as a transitional emotional state (STAIstate); each subscale ranges from 20 to 80, and higher scores indicate a greater level of anxiety [30].

\section{Structural and Resting-State Functional MRI Acquisition Parameters}

Imaging data were collected on a Siemens 3T Prisma wholebody scanner with vendor-provided 64-channel head coil (Siemens Healthcare, Erlangen, Germany). High-resolution structural data (0.8-mm isotropic voxels) were acquired using a T1-weighted MPRAGE sequence with a duration of $7 \mathrm{~min}$ $50 \mathrm{~s}$ (in-plane acceleration factor of 2). Scan parameters for TR, TE, TI, and flip angle were $2.4 \mathrm{~s}, 2.18 \mathrm{~ms}, 1.04 \mathrm{~s}$, and $8^{\circ}$. 
Anatomical scans were immediately followed by resting-state scans, during which subjects were asked to stay awake and keep their eyes fixated on a crosshair. Four resting-state sessions per participant were acquired, with two scans of diffusion MRI in AP-PA directions in the middle. Scan parameters (T2*-weighted EPI sequence) for TR, TE, flip angle, echo spacing, and bandwidth were $800 \mathrm{~ms}, 37 \mathrm{~ms}, 85^{\circ}, 0.58 \mathrm{~ms}$, and $2290 \mathrm{~Hz}$ per pixel. Seventy-two interleaved (ascending/ foot-head) slices were collected in the AC-PC plane using an auto-align procedure to minimize inter-subject variability in data acquisition. Combination of $64 \mathrm{ch}$ array coil and simultaneous multi-slice (SMS) acquisition (multiband factor of 8) provided high temporal sampling (420 time points during an acquisition window of $5 \mathrm{~min}$ and $46 \mathrm{~s}$; four runs) and spatial resolution ( $2 \mathrm{~mm}$ isotropic) while maintaining whole-brain coverage (including the entire cerebellum).

\section{Data Processing: Seed-to-Voxel Functional Connectivity Analysis}

Resting-state data were realigned and spatially normalized to the MNI template using SPM12 (Wellcome Department of Imaging Neuroscience; www.fil.ion.ucl.ac.uk/spm). Structural images were segmented into white matter (WM), gray matter, and cerebrospinal fluid (CSF) using SPM12. The CONN Toolbox [31] was used to compute whole-brain correlation maps from the seed regions of interest (ROIs). ROIs included the whole DN (as defined using the SUIT DN mask [32]), and three functional subterritories of $\mathrm{DN}$ that were defined in a previous study by our group [26], including default-mode network, motorsalience, and visual functional regions (see Fig. 1). The CONN Toolbox uses an anatomical component-based correction method (aCompCor [33]) for denoising BOLD time series and integrates quality assurance (QA) methods to address the deleterious effects of motion artifacts (Artifact Detection Tools, www.nitrc.org/projects/ artifact_detect). There was no between-group difference in the number of motion outliers and maximum and mean head motion. Band-pass filtering was carried out at 0 . 008-0.09 Hz. Time points with a mean signal intensity beyond three standard deviations from the global mean signal and 0.4-mm scan-to-scan motion (about one-fifth the acquisition voxel size) were flagged as problematic scans and were regressed out along with six realignment parameters (along with derivatives) and physiological sources of noise (three principal components of WM, and three principal components of CSF segments, using aCompCor [33]). WM and CSF segments were derived from the structural images using the segmentation routine in SPM12. Because of the small size of the DN, unsmoothed data were used for data analysis to minimize partial volume effects from structures close to DN [34].
Whole-brain Pearson's correlation maps derived from denoised time series from whole DN and the three DN functional territories were converted to $z$-scores using Fisher's $r$ to $z$ transformation to carry out second-level general linear model (GLM) analyses.

\section{Data Processing: Second-Level GLM Analysis}

Seed-to-voxel analysis was carried out using the whole DN as a seed, as well as using the unique effect of each of the three functional territories (DMN, salience-motor, and visual). The unique effect of each functional territory [35] was calculated using a previously described method [26]. Specifically, the DMN unique effect (FT1) was calculated as DMN > (salience-motor and visual), salience-motor unique effect (FT2) was calculated as salience-motor $>$ (DMN and visual), and visual unique effect (FT3) was calculated as visual $>$ (DMN and salience-motor). Statistical significance thresholding for between-group effects included $p<0.001$ (two-sided) at the voxel level and $p<0.05$ false discovery rate (FDR) correction at the cluster level.

\section{Symptom Correlation Analyses}

For all three functional territories, correlations between resting-state fMRI correlations and STAI scores were calculated in both $\mathrm{HC}$ and Anx groups, with a voxel threshold of $p<0.001$ and a cluster-forming threshold of $p<0.05$ (FDR corrected).

\section{Results}

\section{Second-Level GLM Analysis}

Within functional sub-regions of DN (see Fig. 1), statistically significant differences were detected only for the saliencemotor territory (FT2), revealing increased functional connectivity with pre- and postcentral cerebral cortices (peak coordinate at $(-34,-28,70)$ ) (Fig. 2). For both $\mathrm{HC}$ and Anx groups, within-group seed-to-voxel functional connectivity analyses for FT2 (Fig. 1, top panel) showed functional connectivity to cerebral cortical salience-motor regions including the primary motor cortex and supplementary motor area, as well as the bilateral insula, dorsal anterior cingulate cortex, anterior supramarginal gyrus, and rostral middle frontal gyrus. The results were significant after covarying for medication use. Using the whole DN as a seed did not reveal any statistically significant differences between $\mathrm{HC}$ and Anx, highlighting the relevance for investigating the functional parcellations of DN. 
Fig. 2 Top: Within-group results (overlaid on surface maps in CONN) using functional connectivity calculated from the salience-motor FT of the DN (FT2), at voxel-level height threshold of $p<0.001$ (two-sided) and cluster size FDR correction of $p<0.05$. Bottom: Between-group results after controlling for medication use (Anx $>\mathrm{HC})$ at voxellevel height threshold of $p<0.001$ (two-sided) and cluster size FDR correction of $p<0.05, T=5.15$.

Bar plots provide data for the significant cluster (precentral and postcentral cerebral cortex) in Anx and $\mathrm{HC}$
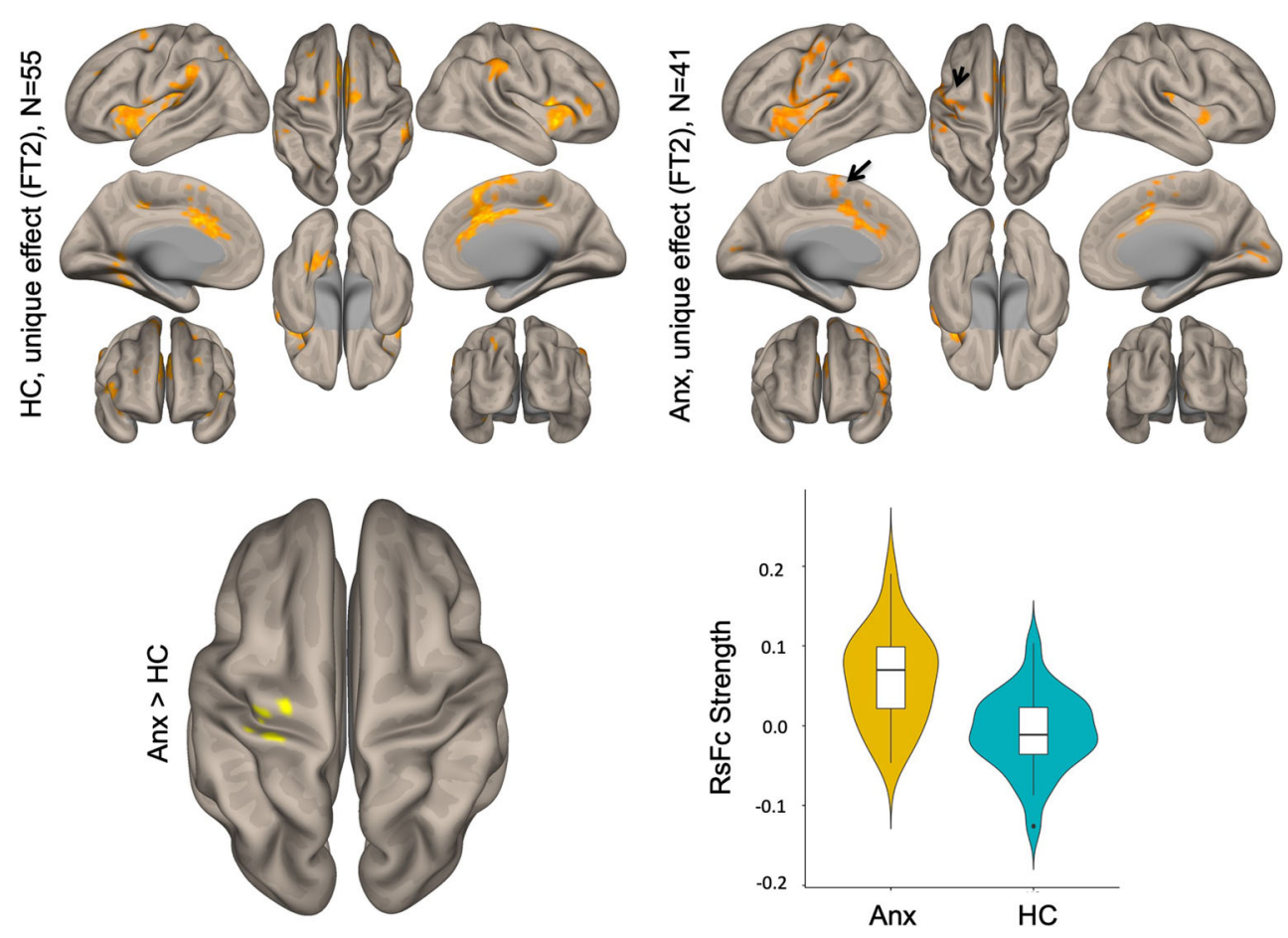

\section{Symptom Correlation Analyses}

To examine individual differences within each group, correlation analyses between functional connectivity and STAI scores were conducted separately for $\mathrm{HC}$ and Anx groups. Within HC, STAI-trait scores and functional connectivity between the salience-motor DN FC and cerebral motor/ somatosensory cortex $(20,-8,70)$ showed a significant correlation, linking higher trait anxiety level to stronger connectivity between salience-motor DN FT and cerebral cortical motor areas (Fig. 3). There was no significant cluster with
STAI-trait scores within the Anx group. STAI-state scores did not reveal any significant difference in either group.

\section{Discussion}

We show for the first time that functional connectivity alterations between cerebellar output structures and cerebral cortical areas are associated with adolescent anxiety. Specifically, hyperconnectivity was detected between DN salience-motor FT and primary motor and somatosensory cortices in
Fig. 3 Whole-brain correlation between STAI-trait scores in healthy controls and saliencemotor DN FT-motor/somatosensory cortex functional connectivity, thresholded at a height threshold of $p<0.001$, clustercorrected at $p<0.05$ FDR. $R^{2}=$ 0.41
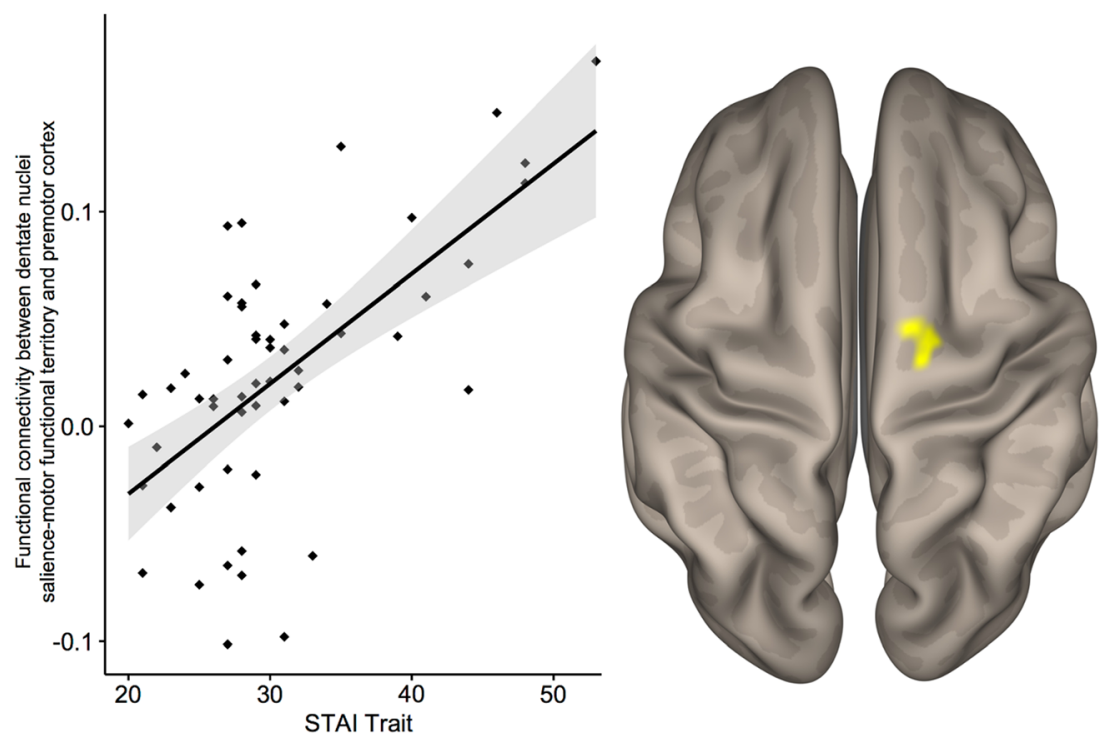
adolescents with anxiety disorders compared to HC. No anxiety-related differences were observed with default mode or visual territories or all combined territories of the DN. Within HC, stronger functional connectivity of saliencemotor DN to motor/somatosensory cortex correlated with higher trait anxiety. Taken together, this new evidence illustrates the use of DN functional sub-divisions as a relevant structure to detect functional differences in psychiatric disease and highlights the role of the DN as a potential target for disease prediction or prevention of affective disorders.

\section{Cerebellar-Cortical Salience-Motor Network in Anxiety}

Evidence from both human and animal studies has established that the cerebellum is connected with various parts of anxiety circuitry, including the insula, basal ganglia, and ventral tegmental area (VTA) (see [8]) for review). Cerebellar connections with cortical and subcortical areas relevant in sensorimotor perception and anticipation of stimulus underpin the nonmotor role of the cerebellum in anxiety. The cerebellar vermis, which contains the fastigial and dentate nuclei, is referred to as the "limbic cerebellum" for its connections to the mesolimbic dopaminergic pathway that originate from the VTA to the nucleus accumbens [36]. The dentate nucleus forms direct monosynaptic excitatory connections with neurons in the VTA [37], which is one of the key subcortical structures that is activated as part of the salience network [38]. Then, the dopaminergic fibers of the meso-cortico-limbic system project to motor cortical fields, mainly to the pre- and postcentral gyrus [39]. Hypoactivations in the cerebellar vermis and subcortical regions in the dopaminergic pathways have been associated with disturbed predictive motor timing paradigm [36].

Also, the insula sends efferent projections to the sensorimotor cortex from which it receives reciprocal afferent projections, forming the salience-motor network [40, 41]. Neuroimaging and invasive stimulation studies in humans support a physiological coupling between sensorimotor systems and stimulus-driven attentional processes [38, 40-44].

The cerebellum also receives inputs from the subthalamic nucleus of the basal ganglia, indicating that the cerebellum may be a key substrate for reward-related signals during learning [45]. Reward-based communication of the basal ganglia and the cerebellum has been highlighted during predictive motor timing tasks [46]. The salience-motor network plays an important role in detecting behaviorally relevant stimuli by mediating the switch between the DMN and task-positive central-executive network and permitting response to the stimuli [47]. The hyperconnectivity that we report in the DN salience-motor FT points to the possibility that there is a maladaptive attribution of salience to internal and environmental stimuli in anxious individuals [48]. It can also be interpreted as the discrepancy in the "internal model" of the cerebellar system that false internal representation of external stimuli would generate unsuited sensorimotor response, which leads to physiological stress and anxiety state [49].

Besides anatomical investigations, other studies of cerebellar function also support a role of the cerebellum in fear and anxiety in animals and humans. In rodent models, manipulations on cerebellar functioning impaired anxiety-related behaviors $[50,51]$. Others have shown a cerebellar role in salience attribution to avoid harmful stimuli $[14,16,52]$. Patients with anxiety disorders also show changes in cerebellar activity and connectivity with anxiety-related brain areas. A few studies observed increased cerebellar activation in social anxiety disorder $[12,13]$ and specific phobia $[53,54]$. Enhanced connectivity between the cerebellum and amygdala has been replicated several times across age range and symptom severity $[5,7,15]$.

Functional connectivity differences between adolescents with anxiety disorders and $\mathrm{HC}$ were observed specifically in the salience-motor territory of the $\mathrm{DN}$; the salience network has clear associations with fear and anxiety processing and is connected to sensorimotor processing systems in the brain as discussed earlier. The salience network is implicated in detecting emotional salience and triggering cognitive regulation [38]. Individuals with high trait anxiety or anxiety disorders have shown aberrance in the salience network. Weaker within-network salience connectivity has been associated with adolescents with higher trait anxiety and patients with social anxiety disorder, suggesting impaired ability in emotion regulation and overreaction to threatening stimuli $[20,55,56]$. One study on healthy young adults suggested that differential resting-state connectivity between the cerebellum and executive and salience cortical regions correlated with behavioral inhibition, which may have a mediating role in anxiety vulnerability [19].

\section{Symptom Correlation}

Within the group of HC, STAI-trait scores correlated with functional connectivity between the premotor cortex and the salience-motor FT of the DN (Fig. 2). The somatosensory cortex is involved in emotional processing through its connection to the amygdala through the insula [57, 58]. After early evaluations of emotional significance are conducted through amygdala interaction with thalamus and limbic regions, somatosensory and related cerebral cortical areas take in for higher order re-evaluation of emotional perception to establish emotional salience [59] and generate fear memory [60]. Thus, people with higher alertness and sensitivity to stress stimuli may bring in more involvement of the somatosensory cortex displayed as heightened activity. It has also been reported that people with specific phobia show higher activation in the somatosensory cortex [61], and heightened activity in this 
area may contribute to difficulties in emotion regulation and lower self-control [62, 63]. Trait anxiety does not necessarily predict conversion to anxiety disorders but is an index of vulnerability to anxiety disorders. Individuals with high trait anxiety and those diagnosed with anxiety disorders share common disruptions in brain activation and connectivity $[64,65]$. Individual differences in state anxiety, although not detected in this study, have also been correlated with increased fluctuations of activation in the right postcentral gyrus and right precentral gyrus and with connectivity between the postcentral gyrus and left cerebellum gyrus [21, 66]. The relationship between DN salience-motor FT connectivity and anxious symptoms may be shown in other populations with anxious symptoms [67].

\section{Limitations and Future Directions}

First, our findings are based on exploratory analyses of cerebellar output structure that suggest overarching alterations in the cortical-cerebellar salience-motor network but do not specify the direction of connectivity. While DN functional connectivity may not uniquely correspond to unidirectional communication between the cerebellar cortex and extracerebellar structures, DN is the largest location of synapses for anatomical connections linking the cerebellar cortex to the thalamus and ultimately to the cerebral cortex. It is therefore reasonable to consider that DN functional connectivity is predominantly a measure of cerebellar functional output. Since we have understanding of anatomical connections between the cerebellum and cortical and subcortical regions of the saliencemotor network, future studies can use causal modeling to characterize the effective connectivity between those regions and examine the directionality of the communication within the cortical-subcortical-cerebellar network.

Second, 44\% of our Anx group were taking psychotropic medications. To overcome this limitation, we covaried for medication use in the between-group analyses. The number of adolescents not on medication use was small $(n=18)$, and STAI score correlation calculations within this subsample would have resulted in a substantial loss of statistical power making false-negative findings very likely; STAI score correlation analyses were thus performed on the full sample of the Anx group. We did not have information on behavioral therapy and thus could not control for this variable. The impact of behavioral therapy on the brain's functional connectivity could have blurred individual differences in correlation between brain networks and anxiety symptoms within Anx as well. More generally, our findings provide only correlational evidence to support altered DN functional connectivity in anxiety disorders. Interventional studies such as non-invasive stimulation experiments or lesion-based analyses may establish a causal link between anxiety and alterations in DN functional connectivity.

\section{Conclusion}

These findings advance our understanding of the cerebellar-cortical salience-motor network in anxiety disorders by identifying abnormal functional connectivity of salience-motor territories within DN, a major cerebellar output to the cerebral cortex, in adolescents with anxiety disorders. In addition, our study identified a relationship between trait anxiety level and DN salience-motor FT functional connectivity in adolescents without a diagnosis of anxiety disorder, suggesting DN salience-motor FT as a potential biomarker for abnormal emotional and attentional processing in sub-clinical anxiety. With recent advances in the field of neuromodulation and neurostimulation, these findings also illustrate the idea that the salience-motor territories in DN may be used as an experimental target region for non-invasive neuromodulation for treatment or prevention of anxiety disorders in the near future.

Funding This project was supported by the National Institute of Mental Health, U01MH108168 (JDEG, SWG), and F32MH114525 (NAH). NAH was partially supported by the Brain and Behavior Research Foundation. AY was partially supported by R01EB021265 and U01EB026996. DAP was partially supported by R37MH068376 and R01MH101521. RPA was partially supported by R01MH119771 and R56MH121426. SSG was partially supported by R01EB020740 and P41EB019936. SGH was partly supported by R01AT007257, R01MH099021, and the James S. McDonnell Foundation. This project was made possible by the resources provided by Shared Instrumentation Grants 1S10RR023401, 1S10RR019307, and 1S10RR023043.

\section{Compliance with Ethical Standards}

Conflict of Interest Over the past 3 years, Dr. Pizzagalli has received consulting fees from Akili Interactive Labs, BlackThorn Therapeutics, Boehringer Ingelheim, Compass Pathway, Otsuka Pharmaceuticals, and Takeda Pharmaceuticals; one honorarium from Alkermes; and research funding from NIMH, Dana Foundation, Brain and Behavior Research Foundation, Millennium Pharmaceuticals. In addition, he has received stock options from BlackThorn Therapeutics.

Disclaimer The content is solely the responsibility of the authors and does not necessarily represent the official views of the National Institutes of Health or of any other sponsor.

Open Access This article is licensed under a Creative Commons Attribution 4.0 International License, which permits use, sharing, adaptation, distribution and reproduction in any medium or format, as long as you give appropriate credit to the original author(s) and the source, provide a link to the Creative Commons licence, and indicate if changes were made. The images or other third party material in this article are included in the article's Creative Commons licence, unless indicated otherwise in a credit line to the material. If material is not included in the article's Creative Commons licence and your intended use is not permitted by statutory regulation or exceeds the permitted use, you will need to obtain 
permission directly from the copyright holder. To view a copy of this licence, visit http://creativecommons.org/licenses/by/4.0/.

\section{References}

1. Kessler RC, Berglund P, Demler O, Jin R, Merikangas KR, Walters EE. Lifetime prevalence and age-of-onset distributions of DSM-IV disorders in the National Comorbidity Survey Replication. Arch Gen Psychiatry. 2005;62(6):593-602. https://doi.org/10.1001/ archpsyc.62.6.593.

2. Merikangas KR, He JP, Burstein M, Swanson SA, Avenevoli S, Cui L, et al. Lifetime prevalence of mental disorders in U.S. adolescents: results from the National Comorbidity Survey Replication-Adolescent Supplement (NCS-A). J Am Acad Child Adolesc Psychiatry. 2010;49(10):980-9. https://doi.org/10.1016/j. jaac.2010.05.017.

3. McLaughlin KA, Garrad MC, Somerville LH. What develops during emotional development? A component process approach to identifying sources of psychopathology risk in adolescence. Dialogues Clin Neurosci. 2015;17(4):403-10.

4. Essau CA, Lewinsohn PM, Olaya B, Seeley JR. Anxiety disorders in adolescents and psychosocial outcomes at age 30. J Affect Disord. 2014;163:125-32. https://doi.org/10.1016/j.jad.2013.12. 033.

5. Liu WJ, Yin DZ, Cheng WH, Fan MX, You MN, Men WW, et al. Abnormal functional connectivity of the amygdala-based network in resting-state FMRI in adolescents with generalized anxiety disorder. Med Sci Monit. 2015;21:459-67. https://oi.org/10.12659/ msm.893373.

6. Monk CS, Telzer EH, Mogg K, Bradley BP, Mai X, Louro HM, et al. Amygdala and ventrolateral prefrontal cortex activation to masked angry faces in children and adolescents with generalized anxiety disorder. Arch Gen Psychiatry. 2008;65(5):568-76. https:// doi.org/10.1001/archpsyc.65.5.568.

7. Roy AK, Fudge JL, Kelly C, Perry JS, Daniele T, Carlisi C, et al. Intrinsic functional connectivity of amygdala-based networks in adolescent generalized anxiety disorder. J Am Acad Child Adolesc Psychiatry. 2013;52(3):290-299.e292. https://doi.org/10. 1016/j.jaac.2012.12.010.

8. Moreno-Rius J. The cerebellum in fear and anxiety-related disorders. Prog Neuro-Psychopharmacol Biol Psychiatry. 2018;85:2332. https://doi.org/10.1016/j.pnpbp.2018.04.002.

9. Perusini JN, Fanselow MS. Neurobehavioral perspectives on the distinction between fear and anxiety. Learn Mem. 2015;22(9): 417-25. https://doi.org/10.1101/lm.039180.115.

10. Talati A, Pantazatos SP, Schneier FR, Weissman MM, Hirsch J. Gray matter abnormalities in social anxiety disorder: primary, replication, and specificity studies. Biol Psychiatry. 2013;73(1):75-84. https://doi.org/10.1016/j.biopsych.2012.05.022.

11. Hilbert K, Evens R, Maslowski NI, Wittchen HU, Lueken U. Neurostructural correlates of two subtypes of specific phobia: a voxel-based morphometry study. Psychiatry Res. 2015;231(2): 168-75. https://doi.org/10.1016/j.pscychresns.2014.12.003.

12. Evans KC, Wright CI, Wedig MM, Gold AL, Pollack MH, Rauch SL. A functional MRI study of amygdala responses to angry schematic faces in social anxiety disorder. Depress Anxiety. 2008;25(6): 496-505. https://doi.org/10.1002/da.20347.

13. Nakao T, Sanematsu H, Yoshiura T, Togao O, Murayama K, Tomita M, et al. fMRI of patients with social anxiety disorder during a social situation task. Neurosci Res. 2011;69(1):67-72. https://doi.org/10.1016/j.neures.2010.09.008.
14. Warwick JM, Carey P, Jordaan GP, Dupont P, Stein DJ. Resting brain perfusion in social anxiety disorder: a voxel-wise whole brain comparison with healthy control subjects. Prog NeuroPsychopharmacol Biol Psychiatry. 2008;32(5):1251-6. https://doi. org/10.1016/j.pnpbp.2008.03.017.

15. Etkin A, Prater KE, Schatzberg AF, Menon V, Greicius MD. Disrupted amygdalar subregion functional connectivity and evidence of a compensatory network in generalized anxiety disorder. Arch Gen Psychiatry. 2009;66(12):1361-72. https://doi.org/10. 1001/archgenpsychiatry.2009.104.

16. Habas C, Kamdar N, Nguyen D, Prater K, Beckmann CF, Menon $\mathrm{V}$, et al. Distinct cerebellar contributions to intrinsic connectivity networks. J Neurosci. 2009;29(26):8586-94. https://doi.org/10. 1523/jneurosci.1868-09.2009.

17. Sang L, Qin W, Liu Y, Han W, Zhang Y, Jiang T, et al. Restingstate functional connectivity of the vermal and hemispheric subregions of the cerebellum with both the cerebral cortical networks and subcortical structures. Neuroimage. 2012;61(4):1213-25. https:// doi.org/10.1016/j.neuroimage.2012.04.011.

18. Yuan M, Zhu H, Qiu C, Meng Y, Zhang Y, Shang J, et al. Group cognitive behavioral therapy modulates the resting-state functional connectivity of amygdala-related network in patients with generalized social anxiety disorder. BMC Psychiatry. 2016;16:198. https:// doi.org/10.1186/s12888-016-0904-8.

19. Caulfield MD, Zhu DC, McAuley JD, Servatius RJ. Individual differences in resting-state functional connectivity with the executive network: support for a cerebellar role in anxiety vulnerability. Brain Struct Funct. 2016;221(6):3081-93. https://doi.org/10.1007/ s00429-015-1088-6.

20. Geng H, Li X, Chen J, Li X, Gu R. Decreased intra- and intersalience network functional connectivity is related to trait anxiety in adolescents. Front Behav Neurosci. 2015;9:350. https://doi.org/ 10.3389/fnbeh.2015.00350

21. Li X, Zhang M, Li K, Zou F, Wang Y, Wu X, et al. The altered somatic brain network in state anxiety. Front Psychiatry. 2019;10: 465. https://doi.org/10.3389/fpsyt.2019.00465.

22. Middleton FA, Strick PL. Anatomical evidence for cerebellar and basal ganglia involvement in higher cognitive function. Science. 1994;266(5184):458-61. https://doi.org/10.1126/science.7939688.

23. Schmahmann JD, Pandya DN. The cerebrocerebellar system. Int Rev Neurobiol. 1997;41:31-60. https://doi.org/10.1016/s00747742(08)60346-3.

24. Buckner RL, Krienen FM, Castellanos A, Diaz JC, Yeo BTT. The organization of the human cerebellum estimated by intrinsic functional connectivity. J Neurophysiol. 2011;106(5):2322-45. https:// doi.org/10.1152/jn.00339.2011.

25. Guell X, Schmahmann JD, Gabrieli JDE, Ghosh SS. Functional gradients of the cerebellum. eLife. 2018;7:e36652. https://doi.org/ 10.7554/eLife.36652.

26. Guell X, D'Mello AM, Hubbard NA, Romeo RR, Gabrieli JDE, Whitfield-Gabrieli S, et al. Functional territories of human dentate nucleus. Cereb Cortex. 2020;30(4):2401-17. https://doi.org/10. 1093/cercor/bhz247.

27. Hubbard NA, Siless V, Frosch IR, Goncalves M, Lo N, Wang J, et al. Brain function and clinical characterization in the Boston adolescent neuroimaging of depression and anxiety study. Neuroimage Clin. 2020;27:102240. https://doi.org/10.1016/j.nicl. 2020.102240 .

28. Siless V, Hubbard NA, Jones R, Wang J, Lo N, Bauer CCC, et al. Image acquisition and quality assurance in the Boston Adolescent Neuroimaging of Depression and Anxiety study. Neuroimage Clin. 2020;26:102242. https://doi.org/10.1016/j.nicl.2020.102242.

29. Spielberger CD, Sydeman SJ. State-Trait Anxiety Inventory and State-Trait Anger Expression Inventory. In: The use of 
psychological testing for treatment planning and outcome assessment. Hillsdale: Lawrence Erlbaum Associates, Inc.; 1994. p. 292 321.

30. Julian LJ. Measures of anxiety: State-Trait Anxiety Inventory (STAI), Beck Anxiety Inventory (BAI), and Hospital Anxiety and Depression Scale-Anxiety (HADS-A). Arthritis Care Res. 2011;63 Suppl 11:S467-72. https://doi.org/10.1002/acr.20561.

31. Whitfield-Gabrieli S, Nieto-Castanon A. Conn: a functional connectivity toolbox for correlated and anticorrelated brain networks. Brain Connect. 2012;2(3):125-41. https://doi.org/10.1089/brain. 2012.0073.

32. Diedrichsen J, Maderwald S, Kuper M, Thurling M, Rabe K, Gizewski ER, et al. Imaging the deep cerebellar nuclei: a probabilistic atlas and normalization procedure. Neuroimage. 2011;54(3): 1786-94. https://doi.org/10.1016/j.neuroimage.2010.10.035.

33. Behzadi Y, Restom K, Liau J, Liu TT. A component based noise correction method (CompCor) for BOLD and perfusion based fMRI. Neuroimage. 2007;37(1):90-101. https://doi.org/10.1016/j. neuroimage.2007.04.042.

34. Bernard JA, Peltier SJ, Benson BL, Wiggins JL, Jaeggi SM, Buschkuehl M, et al. Dissociable functional networks of the human dentate nucleus. Cereb Cortex. 2014;24(8):2151-9. https://doi.org/ 10.1093/cercor/bht065.

35. McClure EB, Monk CS, Nelson EE, Parrish JM, Adler A, Blair RJ, et al. Abnormal attention modulation of fear circuit function in pediatric generalized anxiety disorder. Arch Gen Psychiatry. 2007;64(1):97-106. https://doi.org/10.1001/archpsyc.64.1.97.

36. Lošák J, Hüttlová J, Lipová P, Marecek R, Bareš M, Filip P, et al. Predictive motor timing and the cerebellar vermis in schizophrenia: an fMRI study. Schizophr Bull. 2016;42(6):1517-27. https://doi. org/10.1093/schbul/sbw065.

37. Carta I, Chen CH, Schott AL, Dorizan S, Khodakhah K. Cerebellar modulation of the reward circuitry and social behavior. Science. 2019;363(6424):eaav0581. https://doi.org/10.1126/science. aav0581.

38. Seeley WW, Menon V, Schatzberg AF, Keller J, Glover GH, Kenna H, et al. Dissociable intrinsic connectivity networks for salience processing and executive control. J Neurosci. 2007;27(9): 2349-56. https://doi.org/10.1523/jneurosci.5587-06.2007.

39. Hosp JA, Coenen VA, Rijntjes M, Egger K, Urbach H, Weiller C, et al. Ventral tegmental area connections to motor and sensory cortical fields in humans. Brain Struct Funct. 2019;224(8):283955. https://doi.org/10.1007/s00429-019-01939-0.

40. Mesulam MM, Mufson EJ. Insula of the old world monkey. III: efferent cortical output and comments on function. J Comp Neurol. 1982;212(1):38-52. https://doi.org/10.1002/cne.902120104.

41. Mufson EJ, Mesulam MM. Insula of the old world monkey. II: afferent cortical input and comments on the claustrum. J Comp Neurol. 1982;212(1):23-37. https://doi.org/10.1002/cne. 902120103.

42. Deen B, Pitskel NB, Pelphrey KA. Three systems of insular functional connectivity identified with cluster analysis. Cereb Cortex. 2011;21(7):1498-506. https://doi.org/10.1093/cercor/bhq186.

43. Stephani C, Fernandez-Baca Vaca G, Maciunas R, Koubeissi M, Luders HO. Functional neuroanatomy of the insular lobe. Brain Struct Funct. 2011;216(2):137-49. https://doi.org/10.1007/ s00429-010-0296-3.

44. Uddin LQ. Salience processing and insular cortical function and dysfunction. Nat Rev Neurosci. 2015;16(1):55-61. https://doi.org/ $10.1038 / \mathrm{nrn} 3857$.

45. Bostan AC, Dum RP, Strick PL. The basal ganglia communicate with the cerebellum. Proc Natl Acad Sci U S A. 2010;107(18): 8452-6. https://doi.org/10.1073/pnas.1000496107.
46. Lungu OV, Bares M, Liu T, Gomez CM, Cechova I, Ashe J. Trialto-trial adaptation: parsing out the roles of cerebellum and BG in predictive motor timing. J Cogn Neurosci. 2016;28(7):920-34. https://doi.org/10.1162/jocn_a_00943.

47. Sridharan D, Levitin DJ, Menon V. A critical role for the right fronto-insular cortex in switching between central-executive and default-mode networks. Proc Natl Acad Sci U S A. 2008;105(34): 12569-74. https://doi.org/10.1073/pnas.0800005105.

48. Robinson OJ, Vytal K, Cornwell BR, Grillon C. The impact of anxiety upon cognition: perspectives from human threat of shock studies. Front Hum Neurosci. 2013;7:203. https://doi.org/10.3389/ fnhum.2013.00203.

49. Hilber P, Cendelin J, Le Gall A, Machado ML, Tuma J, Besnard S. Cooperation of the vestibular and cerebellar networks in anxiety disorders and depression. Prog Neuro-Psychopharmacol Biol Psychiatry. 2019;89:310-21. https://doi.org/10.1016/j.pnpbp. 2018.10.004.

50. Otsuka S, Konno K, Abe M, Motohashi J, Kohda K, Sakimura K, et al. Roles of Cbln1 in non-motor functions of mice. J Neurosci. 2016;36(46):11801-16. https://doi.org/10.1523/jneurosci.0322-16. 2016.

51. Sacchetti B, Scelfo B, Tempia F, Strata P. Long-term synaptic changes induced in the cerebellar cortex by fear conditioning. Neuron. 2004;42(6):973-82. https://doi.org/10.1016/j.neuron. 2004.05.012.

52. Shinn AK, Baker JT, Lewandowski KE, Ongur D, Cohen BM. Aberrant cerebellar connectivity in motor and association networks in schizophrenia. Front Hum Neurosci. 2015;9:134. https://oi.org/ 10.3389/fnhum.2015.00134.

53. Ahs F, Pissiota A, Michelgard A, Frans O, Furmark T, Appel L, et al. Disentangling the web of fear: amygdala reactivity and functional connectivity in spider and snake phobia. Psychiatry Res. 2009;172(2):103-8. https://doi.org/10.1016/j.pscychresns.2008. 11.004 .

54. Goossens L, Schruers K, Peeters R, Griez E, Sunaert S. Visual presentation of phobic stimuli: amygdala activation via an extrageniculostriate pathway? Psychiatry Res. 2007;155(2):11320. https://doi.org/10.1016/j.pscychresns.2006.12.005.

55. Gaspar JM, McDonald JJ. High level of trait anxiety leads to salience-driven distraction and compensation. Psychol Sci. 2018;956797618807166:2020-30. https://doi.org/10.1177/ 0956797618807166.

56. Klumpp H, Angstadt M, Phan KL. Insula reactivity and connectivity to anterior cingulate cortex when processing threat in generalized social anxiety disorder. Biol Psychol. 2012;89(1):273-6. https://doi.org/10.1016/j.biopsycho.2011.10.010.

57. Hoistad M, Barbas H. Sequence of information processing for emotions through pathways linking temporal and insular cortices with the amygdala. Neuroimage. 2008;40(3):1016-33. https://doi.org/ 10.1016/j.neuroimage.2007.12.043.

58. Nummenmaa L, Glerean E, Viinikainen M, Jaaskelainen IP, Hari $\mathrm{R}$, Sams M. Emotions promote social interaction by synchronizing brain activity across individuals. Proc Natl Acad Sci U S A. 2012;109(24):9599-604. https://doi.org/10.1073/pnas. 1206095109.

59. Cunningham WA, Zelazo PD. Attitudes and evaluations: a social cognitive neuroscience perspective. Trends Cogn Sci. 2007;11(3): 97-104. https://doi.org/10.1016/j.tics.2006.12.005.

60. Damasio AR, Grabowski TJ, Bechara A, Damasio H, Ponto LL, Parvizi J, et al. Subcortical and cortical brain activity during the feeling of self-generated emotions. Nat Neurosci. 2000;3(10): 1049-56. https://doi.org/10.1038/79871.

61. Rauch SL, Savage CR, Alpert NM, Miguel EC, Baer L, Breiter HC, et al. A positron emission tomographic study of simple phobic 
symptom provocation. Arch Gen Psychiatry. 1995;52(1):20-8. https://doi.org/10.1001/archpsyc.1995.03950130020003.

62. Volkow ND, Wang GJ, Fowler JS, Tomasi D, Baler R. Food and drug reward: overlapping circuits in human obesity and addiction. Curr Top Behav Neurosci. 2012;11:1-24. https://doi.org/10.1007/ 78542011169.

63. Wang GJ, Volkow ND, Thanos PK, Fowler JS. Similarity between obesity and drug addiction as assessed by neurofunctional imaging: a concept review. J Addict Dis. 2004;23(3):39-53. https://doi.org/ 10.1300/J069v23n03 04.

64. Etkin A, Wager TD. Functional neuroimaging of anxiety: a metaanalysis of emotional processing in PTSD, social anxiety disorder, and specific phobia. Am J Psychiatry. 2007;164(10):1476-88. https://doi.org/10.1176/appi.ajp.2007.07030504.

65. Sylvester CM, Corbetta M, Raichle ME, Rodebaugh TL, Schlaggar BL, Sheline YI, et al. Functional network dysfunction in anxiety and anxiety disorders. Trends Neurosci. 2012;35(9):527-35. https://doi.org/10.1016/j.tins.2012.04.012.

66. Geng H, Wang Y, Gu R, Luo YJ, Xu P, Huang Y, et al. Altered brain activation and connectivity during anticipation of uncertain threat in trait anxiety. Hum Brain Mapp. 2018;39(10):3898-914. https://doi.org/10.1002/hbm.24219.

67. Roy B, Ehlert L, Mullur R, Freeby MJ, Woo MA, Kumar R, et al. Regional brain gray matter changes in patients with type 2 diabetes mellitus. Sci Rep. 2020;10(1):9925. https://doi.org/10.1038/ s41598-020-67022-5 (Accession No. 32555374).

Publisher's Note Springer Nature remains neutral with regard to jurisdictional claims in published maps and institutional affiliations. 